\title{
How to Develop Modern Agriculture and Promote New Rural Construction
}

\author{
Li Jiang \\ Jingchu University of Technology, Jingmen Hubei 448000 China
}

Keywords: modern agriculture; new rural construction; methods; meaning.

\begin{abstract}
Along with the constant development of society, Chinese economy development has entered a new stage. Consequently, rural economy has also gained strong development, which cannot leave agricultural development. In the current society, to push rural construction needs to strongly develop modern agriculture and make effective combination with local reality, focusing on farmers' integrated awareness in the modern agricultural development and the constant promotion of talent quality with the assistance of technological power. In the process of implementing land intensification, the arable land should be protected and the rural surplus labor forces shifting should be handled to reform the financial system of rural development. At the same time, we must continue to increase financial support and fundamentally change the growth mode of agriculture, thus ensuring the speed and quality of Chinese agricultural development. At present, the development of modern agriculture is an important support for new rural construction, and at the same time it is also the guarantee of food security and the basis for farmers' incomes increase, which is conducive to the sustainable development of Chinese agricultural economy.
\end{abstract}

\section{Introduction}

As for the modern agriculture, this is a process of continuous optimization and improvement under the premise of former agricultural development, and the development of rural productivity, reversion of the agricultural growth mode and ensuring the speed and quality of agricultural development. In terms of the development of modern agriculture, its essence refers to involving in the industrial sector with the continuous penetration of technology, integrating with production factors and market mechanisms and establishing the service system, making traditional agriculture turn into an new process of new agriculture. Therefore, the core of modern agricultural development is scientific, and the development trend of modern agriculture is intensive, and the goal of modern agricultural development is industrialization. As modern agriculture has made breakthroughs in the production limitations of primary agricultural raw materials in traditional agriculture to some extent, the links between farmers and industries have become closer. At the same time, it has also made breakthroughs in the limitations of urban and rural boundaries, achieving the unified development of urban and rural economies and the optimal allocation of resources and complementary advantages.

\section{The Connotation of Modern Agricultural Development}

The development of modern agriculture mainly refers to scientific, commercialized, intensive and industrialized development, which a modern agricultural form that uses high investment to drive high output. The construction process of modern agriculture is a process of developing traditional agriculture and rural productivity. It is a process of transforming the agricultural growth mode and realizing the development of agricultural industrialization. The core of modern agriculture in its development is science and the prominent feature of development is commercialization. The trend of development is intensive development and the ultimate development goal is to achieve the industrialization. 


\section{Function Analysis of the Modern Agricultural Development in the Rural Construction}

\subsection{The Development of Modern Agriculture Is the Industrial Support in the Process of New Rural Construction}

The primary prerequisite in the construction of a new socialist countryside is the development of production, which is the key to solving the "three rural issues". However, the development basis of production is the development of agriculture. Therefore, modern agricultural development must ensure the modernization of agriculture. The development of modern agriculture can arm the agriculture with modern science and technology and constantly increase the food amount and farmers' incomes, which can make the agriculture develop towards multiple functions and help the continuous strengthening of new rural construction. It is the significant industry support of new rural construction, the important basis for Chinese new countryside in the construction process during this period, important material basis of economic social development and significant guarantee of promoting the agricultural competitiveness.

\subsection{The Development of Modern Agriculture Contributes to the Further Increase of Farmers' Incomes}

The solution to the increase of farmers' incomes is the main core object of solving Chinese "three issues". Namely, only by increasing Chinese farmers' incomes can achieve the harmony, stability of countryside society, which is the important material basis of new rural construction. Besides, it can help rural areas stimulate the consumption and broaden consumption market. Especially, it is of great significance to bringing the constant increase of economy by means of expanding the consumption in the process of financial crisis. In addition, the consumption prosperity of rural areas can help the city economy get further development. Therefore, the development of modern agriculture can not only promote the commodity rate of agricultural products and comprehensive profit of agriculture to increase farmers' incomes but make the second and third industry of rural areas get further development. It can help these sectors broaden the employment space to help farmers get more incomes in more parts to guarantee the long-term and continuous incomes increase. Various agricultural products keeping with the era can be produced on the basis of modern agriculture, which is contributed to broadening the international market and create high incomes for farmers in the process of meeting with the demand of domestic agricultural products. Such method can stimulate their input into the agriculture and promote the positives of planting food. What's more, the endowment insurance with low level and wide range should be tried out according to the development level of regional economy so as to guarantee the stable production of agriculture and promote the further development of Chinese agriculture, which is the significant guarantee to constantly improve agricultural technological strength.

\subsection{The Development of Modern Agriculture is an Important Basis for the Sustainable Development of Agriculture}

At present, agriculture implements the basic activities of people's survival and development. It is the department of material production, depending on the natural environment and having rather great influence on the natural environment. However, sustainable development is directly related with the specific survival and development of human beings. As early as in 2007, the polluted arable land in China is up to 150 million mu, and there are 32.5 million mu affected by sewage irrigation, and there are 2 million mu used to store the solid waste and destroyed. In conclusion, the polluted arable land in this stage is up to the one tenth of the total areas. On top of that, China wastes about 12 million tons of food every day due to heavy metal pollution, and the agricultural economy loss is more than 20 billion yuan. Analyzing from the long-term development, this situation has a direct impact on the long-term development of agriculture. However, the development of modern agriculture can help the development and improvement of rural productive forces, promote the further improvement of production capacity and efficiency in the process of agricultural development and promote the comprehensive development of Chinese rural economy. Also, it can guide farmers to use low-toxic pesticides, reduce the use of pesticides and fertilizers, improve the utilization rate, reduce the pollution caused by soil and guide rural areas to realize conservative and intensive land use so as to 
avoid the occurrence of affecting the plowing. In addition, it can also carry out comprehensive monitoring with the surface source pollution of agriculture and comprehensive treatment for the pollution of agricultural surface sources in key river basins. It is helpful to improve the management rate of rural production and domestic sewage, treat the harmless of manure in the farm and alleviate the pollution of agricultural products as far as possible. Therefore, we should focus on the leading products of agriculture in the development of modern agriculture to create an agricultural circular system where industries can depend on each other and products and intermediate products and waste can exchange and a resource system that can be rationally used to protect and improve the ecological environment, promote the sustainable development ability of agriculture and realize the harmonious development between people and nature.

\subsection{The Development of Modern Agriculture Contributes to the Improvement of Food Security}

China is of large population and vast land resources, and per capita arable area in China is rather little. So in order to enhance the food production amount, the economic method should be turned over and modern agriculture should be strongly developed to regard "focusing on the per production and quality and efficiency promotion" as the key point of agricultural development strategy. Increase the input into the agriculture and scientific research and develop and introduce the varieties of good-quality grain so as to enhance the coverage rate of these breeds. Meanwhile, they should make great exploitation with irrigation technology of saving water and enhance the promotion strength of agricultural technology to transform form traditional agriculture to modern one. In the development process of modern agriculture, total grain output should be constantly enhanced and increased by years, but the whole increasing strength and extent is not very big. In addition, they should strengthen the comprehensive supervision with agricultural seeds, fertilizers, agricultural machinery and pesticide market and strictly control the price of agricultural material products, avoiding the continuous price increase and reducing the problems of farmers' incomes. The sage supple of grain should be guaranteed to promote their incomes to get further increase, which is the vital purpose of modern agricultural development.

\section{Effective Measures of Chinese Modern Agriculture Development}

\subsection{Strengthen the Protection of Cultivated Land and Promote the Transparency of Land Acquisition}

The development of modern agriculture needs to promote the utilization rate of land intensification and reduce the cost of farmers' planting so as to achieve the ultimate goal of improving efficiency and increasing income. In recent years, technology has been widely used in agricultural development, and the past family agricultural management method has not been compatible with modern agricultural development requirements., so it is of great necessity to guarantee the circulation system for the right to contract land. It is urgent to protect the arable land, as the extreme lacking problem in China at the present stage, which not only contributes to guaranteeing the fundamental status of agriculture, but ensures Chinese food security. It is a significant choice to push the constant development of Chinese economy. At the same time, a hearing system adapted to the agricultural economic development of the whole socially should be created as soon as possible to promote the further improvement of land use transparency in order to avoid the occurrence of arable land misuse.

\subsection{Give Certain Intellectual Support for the Development of Modern Agriculture on the Basis of Scientific and Technological Progress and Talent Support}

Farmers are the main body of agriculture and rural economy development. The level of their qualities directly influences the increasing degree of incomes. The development of modern agriculture needs to train those new farmers who can adapt to the modern agricultural development. There exists some limit in the potential of arable area expanding due to more people and less lands. So their income increase should be done based on the technological process. At present, rural labor forces have rather low qualities, which is directly related with the transferring scale and rate of rural labor force. Meanwhile, it has also affected the promotion of rural economy, which needs to 
strengthen the training with farmers' agricultural production skills and expand the training scale and regard the training with wide farmers as the key point in agricultural development to make them become modern agricultural runner equipped with market awareness, production skills and management and abilities; while in those agricultural development zones with good conditions, those cooperation groups among professional investors and farmers, leading enterprises and collective economy and operators keeping pace with the era should be encouraged. And various effective policies should be adopted to support them and encourage those farmers who work outside the countryside to bring new technology and capital to rural area to start a business. In this process, effective supporting policies should be adopted to make farmers develop into professional farmers or farmer entrepreneurs.

\subsection{Strengthen the Propaganda to Promote Farmers' Overall Consciousness in the Development of Modern Agriculture}

Farmers are the owners of new rural construction, and modern agriculture cannot leave the positive participation and support of farmers. Farmers' ideology awareness should be enhanced in modern agriculture and their initiative should also be activated in this process. At the same time, they should encourage farmers to promote independent spirit, strengthen the production input and intelligence input, promote the level of scientific ploughing and intensive operation and properly subsidize farmers' capital and labor force input. Also, they can create a good environment for modern agricultural development by means of tax, subsidy and guarantee. Promote farmers to achieve the resource exploitation and enhance the overall awareness of modern agricultural development under the guidance of laws and rules.

\subsection{Strengthen the Importance of "Three Agriculture" Issues}

The solution to the "three rural issues" is an important issue for our party in carrying out its work. The main reasons are as follows: first, agricultural development is a prerequisite for the development of the national economy and a necessary condition for the development of other sectors, which has a direct impact on the stable development of Chinese society; second, rural development still has certain contradictions and problems so far and there are weak development facilities and difficulties in increasing incomes. Therefore, it is necessary to attach more importance to the issue of agriculture, countryside and farmers to ensure the new rural construction of Chinese modern agriculture.

\section{Conclusion}

In conclusion, the new rural construction cannot leave the development of modern agriculture. Therefore, it is very necessary to strengthen the development of modern agriculture and apply scientific policy support to strengthen farmers' overall qualities. And the new science and technology can be applied to promote the development of Chinese modern agriculture development on this basis and new rural construction to make basic guarantee for economic development.

\section{Acknowledgements}

Fund project of China Rural Valley Development Research Center, Hubei Humanities and Social Sciences Research Base.

\section{References}

[1]. Dan Zhao. Study on the Mode of Investment and Financing and the Safeguard Mechanism of Chinese New Rural Housing Construction[D]. Beijing Jiaotong University,2014.

[2]. Gefang Wang. Research on Chinese Urbanization Strategy from the Perspective of Scientific Development Outlook[D]. Shandong Normal University,2013.

[3]. Xiaohai Zhang. The New Rural Construction Mode and Empirical Research in the Mining Area of Shandong Province[D]. China University of Mining and Technology (Beijing),2013. 
[4]. Xia Yu. Research on the Theoretical Innovation of the Party's "Agriculture, Countryside and Farmers" Since the 16th NCCPC[D]. Dalian Maritime University,2013.

[5]. Peng Wang. Study on the Performance Evaluation of Financial Supporting Agriculture under the Background of New Rural Construction[D]. Jilin University,2012 